\title{
Artigo \\ Dessalinizador solar com cobertura piramidal: aperfeiçoamento e análise térmica
}

\author{
Bruno Soares de Carvalho ${ }^{[1]}$, Fabiana Karla de O. M. Varella Guerra ${ }^{[2]}$ \\ [1] Universidade Federal Rural do Semi-árido; bsoares5@yahoo.com.br \\ [2] Universidade Federal Rural do Semi-árido; fkv@ufersa.edu.br \\ Recebido: 18/06/2020; \\ Aceito: 30/07/2020; \\ Publicado: $11 / 09 / 2020$.
}

Resumo: O acesso a água potável ainda é difícil para muitas famílias brasileiras, principalmente as do nordeste do país, que muitas vezes recorrem à água de poços tubulares que em sua maioria tem alta salinidade não sendo indicada para consumo humano. Uma técnica utilizada para tratamento de água salobra é a dessalinização solar, que é uma tecnologia acessível e de baixo custo. O presente trabalho tem como objetivo realizar melhorias em um dessalinizador solar já desenvolvido. com o intuito de aumentar sua eficiência e tornar viável a sua aplicação como uma alternativa ao tratamento de águas salobras de poços tubulares na região do semiárido Potiguar. Para aferir a eficiência do protótipo foram realizadas análises de parâmetros importantes, a saber, temperatura ambiente; temperatura da água destilada; temperatura da coberta e a radiação solar, onde o protótipo demonstrou desempenho satisfatório.

Palavras-chave: Dessalinização Solar, Água Salobra, Tratamento de Água, Eficiência.

Abstract: Access to drinking water is still difficult for many Brazilian families, especially those in the northeast of the country, who often resort to water from tube wells, most of which have high salinity and are not suitable for human consumption. One technique used for brackish water treatment is solar desalination, which is an affordable and low-cost technology. This work aims to make improvements in an already developed solar desalter. with the intention of increasing its efficiency and making its application viable as an alternative to the treatment of brackish water from tube wells in the semi-arid Potiguar region. In order to assess the efficiency of the prototype, analyses of important parameters were performed, namely, room temperature; temperature of the distilled water; temperature of the deck and the solar radiation, where the prototype demonstrated satisfactory performance.

Key-words: Solar Desalination, Saltwater, Water Treatment, Efficiency.

\section{INTRODUÇÃO}

A dessalinização de água por destilador solar é um método simples, mas que tem resultados significativos na melhora dos parâmetros da água de forma economicamente viável. A destilação solar produz água com um grau de pureza elevado, superior as águas comerciais engarrafadas [1]. Um estudo realizado por [2] mostrou que a destilação solar elimina completamente todos os sais, metais pesados, bactérias e micróbios presentes em águas poluídas, assim também como a remoção de vários pesticidas, devido as altas temperaturas e a radiação ultra violeta. [3] afirmam que, diante da escassez de água potável na zona rural, o dessalinizador solar é uma alternativa a ser considerada. 
De acordo com [4] o consumo de água diretamente de rios, lagos, mares e reservatórios subterrâneos não é aconselhável, pois nessas águas existem uma concentração de sais e microrganismos em quantidades que podem ser prejudiciais ao ser humano. Sendo assim, existe uma necessidade de obtenção de água potável a partir de águas salobras e salgadas. Pode-se citar diversas tecnologias para a obtenção de água potável, a saber: osmose inversa, electrodiálise, destilação multiestágio e destilação solar. Destas tecnologias citadas o processo de dessalinização solar é a única renovável e será o objeto de estudo desse artigo.

Por todo o exposto, o presente trabalho tem como objetivo principal realizar melhorias em sistema de dessalinização solar desenvolvido por [5] visando maximizar a sua eficiência, com o intuito de aplicar essa tecnologia para tratamento de poços com alta salinidade.

\section{DESSALINIZADOR SOLAR}

A destilação solar de água não é uma técnica nova para transformar água salobra em potável, Em meados do século IV a.C. Aristóteles demostra um método para transformar água impropria ao consumo, através da evaporação e condensação, em água destilada própria para o consumo [6].

A primeira instalação de um sistema de dessalinização solar moderno foi desenvolvido em 1872 em Las Salinas- Chile pelo engenheiro Sueco Charles Wilson, para fornecer água potável para os animais. A unidade de dessalinização construída tinha 64 tanques de água salgada que absorvia a radiação solar, assim levando a água ao estado de vapor, e condensando em vitrais transparentes inclinados, sendo depois coletadas em tanques para uso posterior [4].

No Brasil, os primeiros protótipos de destiladores solares foram feitos em 1970, pelo Instituto Tecnológico da Aeronáutica- ITA [4]. Ao longo das décadas surgiram novos empreendimentos de dessalinização solar no país, com maior expressividade a partir dos anos 2000 com a necessidade da diversificação da matriz energética brasileira. Um exemplo de um desses empreendimentos foi no estado da Paraíba, onde foi realizada a implementação de um sistema de dessalinização solar em uma comunidade localizada no Município de Remígio, região do Curimataú Paraibano, que tinha por finalidade tratar a agua do assentamento rural e assim possibilitar o acesso á agua de qualidade á esse assentamento, através de uma tecnologia de baixo custo [7] [8] desenvolveu um estudo de um dessalinizador solar convencional no município de Mossoró região do semiárido do Rio Grande do Norte. O protótipo desenvolvido tinha capacidade de armazenamento de 203 litros de água salobra, com cobertura simétrica com dois vitrais, o sistema obteve um rendimento médio de $20 \%$.

Em 2018 [5] desenvolveu um protótipo de dessalinizador solar com cobertura piramidal de baixo custo, com capacidade de armazenamento de 3,75 litros de água salobra, com um rendimento médio de 19,62\%. Já em 2019 [9] desenvolveu um protótipo de dessalinizador solar convencional de baixo custo no Município de Natal-RN. O Protótipo desenvolvido tinha cobertura simétrica com dois vitrais, a eficiência media do protótipo foi de $33 \%$. Foi analisada a influência da profundidade do protótipo, verificou-se que em menores profundidades o rendimento é maior.

\subsection{Funcionamento de um dessalinizador solar}

Os sistemas de dessalinização solar utilizam o mesmo conceito mudando apenas algumas características como a geometria e materiais. O princípio de funcionamento de um destilador solar pode ser entendido como uma simulação dos efeitos naturais do ciclo da água. O esquema geral de funcionamento de um destilador solar é representado pela Figura 1. Que tem como componentes: cobertura, que pode ser de vidro ou plástico, que permite a passagem da radiação solar até a água salobra, bem como posteriormente permitindo sua condensação; 
O reservatório de água salobra; e calha, que permite o escoamento da água destilada nas extremidades dos vitrais para o um reservatório externo.

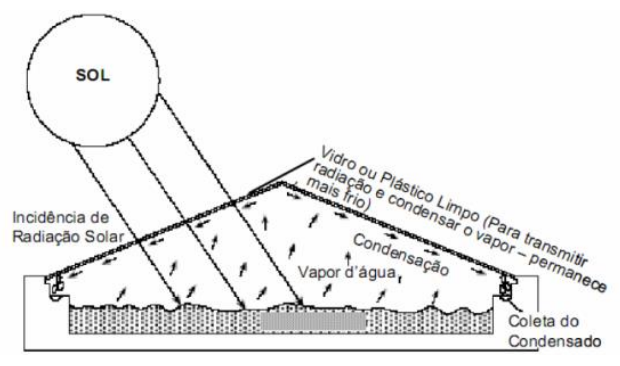

Figura 1: Esquema de um Destilador Solar. Fonte: [10].

Os dessalinizadores solares funcionam utilizando um princípio básico de evaporação e condensação, A água salobra é colocada no tanque formando uma fina camada. Pode haver variação no tamanho e profundida do tanque, e segundo [11] os reservatórios podem ter profundidades de 10 a $20 \mathrm{~mm}$ em reservatórios rasos podendo chegar a $100 \mathrm{~mm}$ ou mais em reservatórios profundos. [12] concluiu que a profundidade do reservatório tem grande influência no rendimento do dessalinizador, sendo profundidade e rendimento inversamente proporcionais. A radiação solar ultrapassa os vitrais chegando até à água que está no reservatório adicionando calor fazendo com que a mesma evapore, ao evaporar a água destilada adere na superfície dos vitrais e escoa até às calhas, e assim sendo armazenada para uso posterior.

Para realizar um projeto de construção ou otimização de um dessalinizador solar é de suma importância conhecer os materiais e as principais partes desse equipamento, para que assim se possa buscar maneiras de maximizar sua eficiência, através de novos arranjos de materiais e processos.

\subsubsection{Tanque}

O tanque é a parte do dessalinizador solar onde a água a ser tratada fica armazenada, e será nesse local para onde os raios solares serão direcionados. O tanque é uma das partes mais importantes do dessalinizador solar, sendo necessário analisar alguns pontos importantes para obter maior eficiência, Segundo [6] a seleção dos materiais para a confecção do tanque constitui um dos principais problemas na construção dos dessalinizadores solares. Ainda segundo [6] para se obter um melhor rendimento, o tanque deve ser aprova d'água e pintado de um cor escura, a superfície do material tem que ser lisa e anticorrosiva, já que está lidando com soluções salinas. O trabalho realizado por [4] mostra que quanto menor a profundidade do reservatório, mais rapidamente é o aumento da temperatura da água salobra. E segundo [6] a profundidade tem uma influencia no rendimento do dessalinizador tendo eficiência máxima entre 1,5 a 2,5 cm de profundidade. Que também é corroborado por [4] que mostra que a produção de destilado diminui com o aumento da profundidade do reservatório.

\subsubsection{Cobertura}

Após o tanque, a cobertura é a parte do dessalinizador mais importante , pois é através dela que os raios solares chegarão até a água no tanque, sendo essa parte do projeto bastante relevante para um bom desempenho do equipamento para [6] a escolha do material tem grande influência no rendimento do sistema, sendo o vidro temperado melhor indicado para esse fim. Além disso a espessura do vidro é um elemento a ser observado, e [4] verificou que uma cobertura com espessura de $3 \mathrm{~mm}$ consegue um acréscimo de 16,5\% na produção em 
comparação com a espessura de $6 \mathrm{~mm}$. Outro fator a ser observado é a inclinação, que segundo [4] o rendimento do sistema é máximo quando a inclinação dos vitrais corresponde à latitude do lugar onde esta instalada.

Muitos são os fatores que afetam o rendimento de um dessalinizador, muitos deles já foram destacados anteriormente, e além disso pode-se destacar algumas perdas decorrente da composição química do material, Segundo [6] cerca de $10 \%$ da radiação solar é refletida, além de perdas por convecção 12,2\% e condução 16\%, entre outras. Assim ainda segundo [6] a eficiência máxima de um dessalinizador solar não ultrapassa 60\%, tendo seus valores ótimos na faixa $38 \%$ e $43 \%$.

\section{MATERIAIS E MÉTODOS}

\subsection{Construção do dessalinizador solar}

Após um estudo detalhado do protótipo desenvolvido por [5] onde foi analisado cada componente do protótipo e os materiais usados para sua confecção, também foram analisadas as características funcionais de cada componente, com o objetivo de encontrar pontos de possível melhoria no desempenho do sistema de dessalinização solar.

\subsubsection{Tanque}

O tanque como já falado anteriormente constitui-se uma das partes mais importantes de um dessalinzador solar, por isso será o primeiro objeto de análise. O reservatório desenvolvido por [5] tinha as seguintes características: área efetiva de dessalinização de $0,0576 \mathrm{~m}^{2}$ e altura de $10 \mathrm{~cm}$, totalizando um volume de $0,00576 \mathrm{~m}^{3}$, a matéria-prima utilizada foi o vidro comum $4 \mathrm{~mm}$ de espessura, com um isolamento de $1 \mathrm{~cm}$ de espessura, composto por isopor e lona preta. Pela análise de referencial já realizada, foram propostas algumas modificações para maximizar a eficiência do tanque, dessa maneira o tanque ficou configurado da seguinte forma: a área de dessalinização permaneceu inalterada $0,0576 \mathrm{~m}^{2}$, e a profundidade do tanque passou a ser de $3 \mathrm{~cm}$.

\subsubsection{Cobertura}

A cobertura é uma das partes essenciais de um dessalinizador solar, e como já mencionado existem algumas características para maximizar a eficiência, A cobertura por exemplo, desenvolvida no protótipo inicial [5], era uma cobertura piramidal, com uma angulação de $25^{\circ}$, Levando em consideração que o dessalinizador será utilizado no Nordeste, esse tipo de geometria tem um melhor aproveitamento [1]. Outra característica observada do protótipo de [5] foi que os raios solares incidiam sobre a calha de escoamento da água, o que resultava na evaporação da mesma antes de ser coletada no reservatório adequado, assim foi aplicada uma camada de fita espelhada, impedindo que os raios solares incidissem sobre a água dessalinizada. A distância da cobertura para a água no interior do reservatório também influencia na eficiência, e no protótipo inicial, desenvolvido por [5], essa distância era de $10 \mathrm{~cm}$. Para se obter uma maior eficiência tal distância foi alterada para $5 \mathrm{~cm}$, corroborando com [6] que afirma que a distância entre a cobertura e a água não deve ser superior à $5 \mathrm{~cm}$. A Figura 2 mostra como é a estrutura da cobertura do protótipo. 


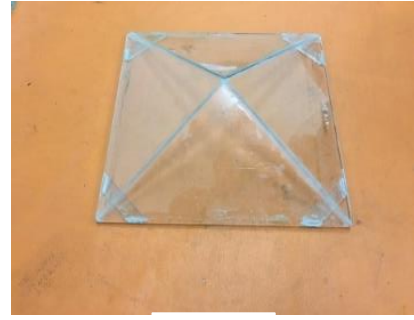

(a)

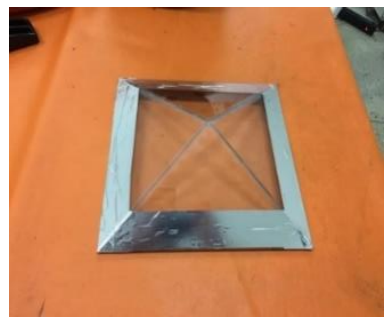

(h)

Figura 2 - Cobertura piramidal antes e depois das modificações. (a) cobertura do protótipo desenvolvido por [5]. (b) cobertura com as modificações propostas. Fonte: [13]

\subsubsection{Isolamento térmico}

O isolamento térmico tem uma função imprescindível para que um dessalinizador solar alcance um bom desempenho diminuindo a perda de calor para o ambiente. No protótipo inicial foram utilizados dois materiais com características distintas para confeccionar o isolamento do tanque, que foram, camadas de isopor $6 \mathrm{~mm}$ intercalado com papel alumínio. No caso, a composição foi de três camadas Isopor- Papel alumínio- Isopor, e o isopor foi utilizado com a finalidade de minimizar o máximo possível a perda de calor por contato, e o papel alumínio para impedir a perda de calor por radiação. Segundo [4] um aumento na espessura do isolamento é acompanhado com um aumento na temperatura da água do reservatório. Assim para maximizar a eficiência no isolamento, foram acrescentadas três camadas de Isopor intercalando com o papel alumínio.

Outro ponto importante a ser considerado, a respeito do isolamento refere-se ao compartimento de condensação do protótipo, para que exista uma máxima condensação é preciso que se tenha um gradiente de temperatura onde a água destilada escoe de uma região mais quente para uma mais fria. Assim, em relação a esse compartimento o mesmo foi revestido com uma camada de papelão $6 \mathrm{~mm}$ e com um material espelhado (fita adesiva espelhada), com o intuito de impedir que a radiação solar entre em contato com a água naquela parede de condensação.

As modificações foram feitas visando maximizar a eficiência do protótipo desenvolvido por [5], com base em protótipos já desenvolvidos, que foram discutidos no referencial teórico. A Figura 3 mostra o protótipo desenvolvido por [5] e o desenvolvido por esse artigo.

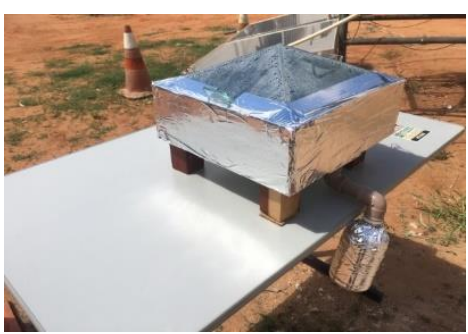

(a)

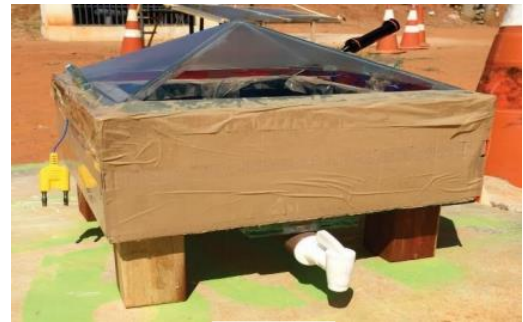

(b)

Figura 3 - Protótipo de dessalinizador solar antes e depois das modificações propostas.

(a) protótipo modificado, (b) protótipo desenvolvido por [5]. Fonte: [13]

\subsection{Metodologia dos ensaios}

Para visualizar todos os parâmetros necessários para aferir a variação de eficiência no protótipo, foram coletados dados a cada 1 hora, a partir das 9:00 horas até às 15:00 horas, durante 4 dias distintos, e o período de coleta dos dados foi do dia 19 á 21 de Junho e no dia 2 de Julho do ano de 2019. Os parâmetros medidos 
foram a temperatura externa da cobertura; a temperatura da água no tanque; a radiação solar; temperatura ambiente; e a velocidade do vento.

O sistema de dessalinização solar desenvolvido é um aperfeiçoamento do protótipo desenvolvido por [5], dessa maneira, os parâmetros medidos nesse trabalho foram semelhantes aos medidos pelo autor do referido trabalho. Os ensaios foram realizados na Universidade Federal rural do semi-árido em Mossoró/RN, nas imediações do prédio Engenharias I, localizado no campus leste da referida instituição. O local foi escolhido de maneira que obtivesse uma melhor incidência solar durante todas as horas de pleno sol, e facilitasse a leitura dos dados in loco. Os equipamentos utilizados para medir os parâmetros foram um anemômetro; um termômetro a laser; um termômetro digital e um medidor de radiação solar. Os equipamentos foram cedidos pelo Laboratório de Engenharia Elétrica e Mecânica da UFERSA.

Para coletar os dados, seguiu-se uma sequência, que foi iniciada medindo a temperatura ambiente, com o anemômetro na função temperatura, e em seguida foi medida a radiação solar com o auxílio do medidor de radiação solar. Após essa etapa, foi medida a temperatura da cobertura, com o auxílio do termômetro a laser, e por fim, foram medidas as temperaturas da água salobra no tanque, também com o anemômetro.

\subsubsection{Eficiência}

A eficiência de um dessalinizador solar é um dos parâmetros de maior relevância para sua viabilização, pois esse parâmetro mede a relação entre a quantidade de radiação solar que chega ate o equipamento e a quantidade destilada final. Para se ter uma mesma medida de comparação a equação de eficiência utilizada foi a mesma de [5], mostrada na Equação 1.

$$
\eta=\frac{Q * 2,3}{G * A}
$$

Onde:

$\eta=$ Eficiência do sistema de destilação

$\mathrm{Q}=$ Quantidade de água destilada ao final de um dia (Litros/Dia)

$\mathrm{G}=$ Média diária de energia acumulada total $\left(\mathrm{MJ} / \mathrm{m}^{2}\right)$

$\mathrm{A}=$ Área útil do destilador $\left(\mathrm{m}^{2}\right)$

\section{RESULTADOS}

O primeiro dia de ensaio analisou o comportamento do protótipo e possíveis melhorias que ainda não tivessem sido observadas. Após algumas horas de exposição do protótipo ao sol foi verificado que a condensação na cobertura ainda não era significativa, mesmo vedando a junção entre a coberta e o tanque como feito por [5]. Após analisar o funcionamento do protótipo, foi percebido que, existia uma grande incidência de raios solares na calha de condensação, que fazia com que a água não condensa-se, Para solucionar tal problema foi colocada uma manta refletora impedindo que os raios solares chegassem até à parede de condensação. A solução implantada mostrou-se satisfatória, aumentando a condensação. Foram utilizados para as análises dos resultados os dados coletados no dia 20/06/2019.

\subsection{Temperaturas ambiente}

Os dados das temperatura ambiente estão expostos no gráfico da Figura 4, que ilustra a variação média de temperatura ao longo do dia de ensaio do dessalinizador solar. 


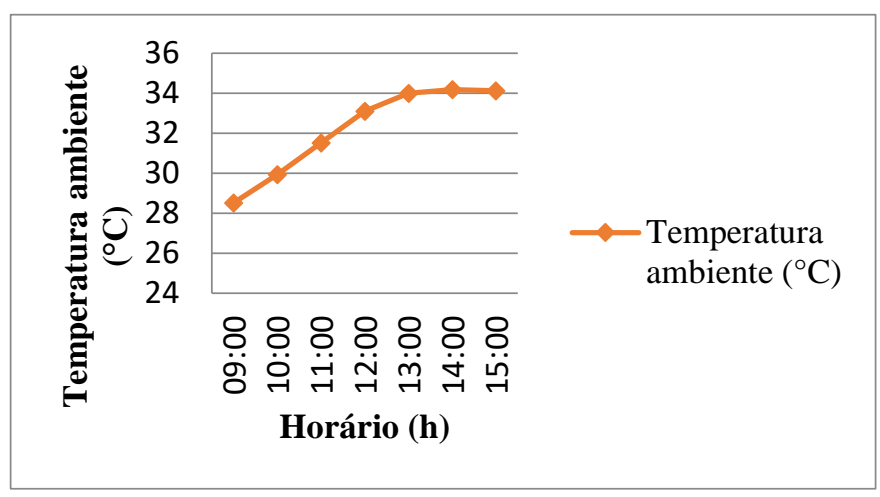

Figura 4: Temperatura ambiente ao longo do tempo. Fonte: [13]

Durante o experimento foi possível observar que as temperaturas não tiveram mudanças bruscas em seus valores, apresentando uma temperatura média de $32{ }^{\circ} \mathrm{C}$ favorável ao experimento [8].

\subsection{Temperatura na superfície da cobertura}

No gráfico da Figura 5 serão analisadas as temperaturas na superfície da cobertura do dessalinizador durante todo o período de experimentação do dia 20/06/2019.

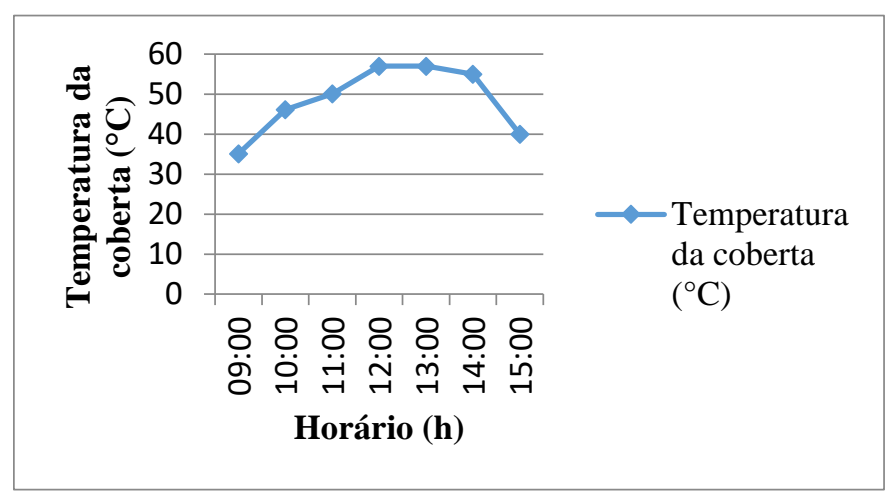

Figura 5: Temperatura da coberta ao longo do tempo. Fonte: [13]

Fonte:

Através da Figura 5, pode-se analisar que no decorrer do experimento a cobertura do protótipo absorveu calor, aumentando assim a sua temperatura media, atingindo uma temperatura média de $48,6{ }^{\circ} \mathrm{C}$, o que é satisfatório, mostrando assim sua capacidade de absorver a energia proveniente do sol. Outro ponto a ser destacado é que das 9:00 horas até às 12:00 horas a temperatura aumentou e a partir das 12:00 horas até às 14:00 horas a temperatura ficou praticamente constante, isso mostra que o material da cobertura atingiu um valor limite de temperatura.

\subsection{Radiação solar}

A Figura 6 mostra a quantidade de radiação média incidente sobre o protótipo de dessalinizador solar, e esse parâmetro é de suma importância, sendo a radiação a responsável por transferir calor para a água salobra. 


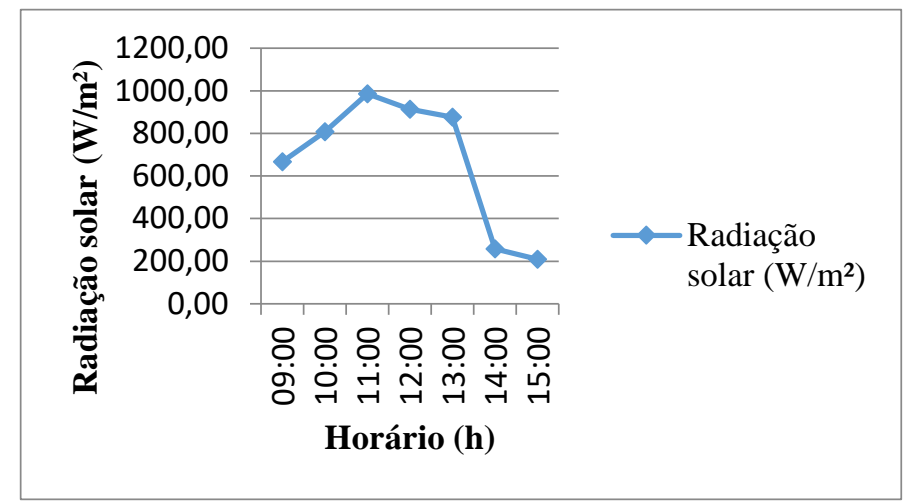

Figura 6: Irradiação solar ao longo do tempo. Fonte: [13]

A Figura 6 mostra que até às 12:00 horas a incidência de radiação solar tem um comportamento crescente, apresentando valores menores logo depois. É válido resaltar que durante o ensaio, por muitas vezes, houve excesso de nebulosidade na região, o que ocasionou uma maior variação da radiação entre às 13:00 horas e ás 14:00 horas, mesmo com periodos de nebulosidade foi obtido valores satisfatorios de radiação solar, para o funionamento adequado do dessalinizador solar. Ao final do periodo analisado, ou seja do dia 20/06/2019, foi calculada uma incidencia de radiação media de $673,99 \mathrm{~W} / \mathrm{m}^{2}$.

\subsection{Temperatura da água salobra}

Um parâmetro importante a ser analisado é a temperatura da água salobra no interior do reservatório, pois ela relaciona a capacidade do protótipo de transformar a radiação recebida, no aquecimento da água salobra. A Figura 7 mostra a variação da temperatura da água salobra no decorrer do dia 20/06/2019.

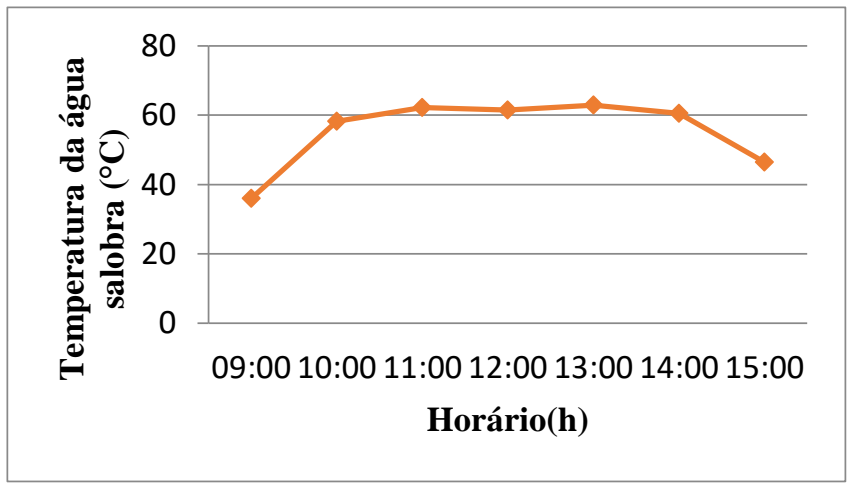

Figura 7- Temperatura da água salobra no reservatório. Fonte: [13]

Uma das funções principais do tanque é a de manter a temperatura da água salobra, ou seja impedir que haja perda de calor para o ambiente, e a Figura 7 mostra que a temperatura no tanque do prototipo a partir das 10:00 horas permanece praticamente constante até o final do ensaio do dia 20/06/2019, o que proporciona um rendimento maior para o sistema. Como medida de comparação, a Figura 8 mostra o desempenho térmico entre o prototipo dessenvolvido por [5], que realizou seus ensaios do dia 14 à 23 de agosto de 2018, e o dessenvolvido por esse artigo. 


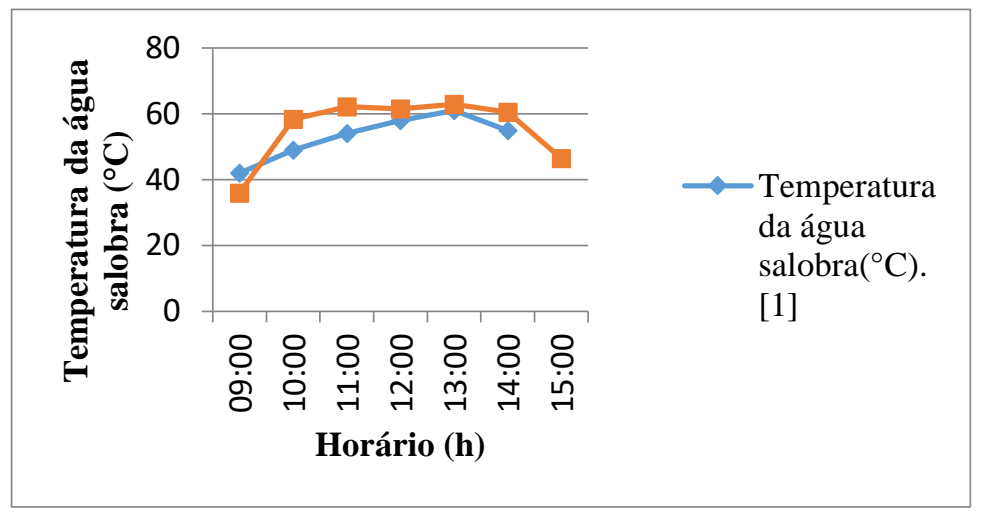

Figura 8- Comparação entre as temperaturas da água salobra no reservatório ao longo do tempo. Fonte: [13]

Através da Figura 8 é possível verificar que a temperatura do reservatório do protótipo dessenvolvido por [5] tem um comportamento cresente atingindo seu máximo às 13:00 horas, enquanto a temperatura do protótipo desenvolvido nesse artigo atinge a mesma temperatura às 10:00 horas da manhã, permanecendo constante áte às 14:00 horas, mostrando assim uma capacidade maior de reter o calor no sistema. Os ensaios feitos por [5] ocorreram em um periodo de 8 horas, iniciando às 8 horas da manhã e encerrando às 14 horas. Foi observado que o local onde os ensaios foram realizados ao lado do Predio Engenharias I, na UFERSA- Mossoró, a incidencia de raios solares são significativas a partir das 9 horas da manhã, seguindo até às 15 horas, por esse motivo os ensaios foram realizados no periodo das 9:00 horas até às 15:00 do dia 20/06/2019.

\subsection{Rendimento}

Todas as partes do protótipo foram desenvolvidas visando alcançar o rendimento máximo possível, e [8] conceitua rendimento como a quantidade de água destilada produzida pelo sistema ao longo do período de análise. Dessa maneira, o rendimento esta ligado intricecamente ao modo de construção do protótipo, aos materiais utilizados e aos fatores climáticos. O ensaio foi realizado no dia 20/06/2019, onde foi adicionado ao tanque do dessalinizador solar $500 \mathrm{ml}$ de água salobra, tendo um resultado final de $110 \mathrm{ml}$ de água dessalinizada.

\subsubsection{Eficiência}

A eficiência como já foi definida anteriormente pode ser calculada pela Equação 1, e para atingir a eficiencia total tem-se que, a quantidade de água deslitada coletada após as 6 horas de ensaio (Q) foi de $110 \mathrm{ml}$ ou $0,11 \mathrm{~L}$. A radiação solar total media coletada $(\mathrm{G})$ foi de $673,99 \mathrm{~W} / \mathrm{m}^{2}$ que equivale à $16,98 \mathrm{MJ} / \mathrm{m}^{2}$, a área útil (A) que é de $0,042 \mathrm{~m}^{2}$. Aplicando os valores coletados no protótipo na Equação 1, o dessalinizador solar apresentou uma eficiencia de 36\%. Em relação ao protótipo desenvolvido por [5], obteve-se um acréscimo de algo em torno de $16 \%$, o que mostra que efetivamente as modificações realizadas foram relevantes e positivas, tendo o sistema aqui proposto uma melhor eficiência.

\section{CONCLUSÃO}

A cidade de Mossoró no estado do Rio Grande do Norte, que esta situada no nordeste Brasileiro, tem elevados níveis de radiação solar durante todo o ano, mesmo a cidade tendo periodos de grande nebulosidade as condições são propícias para o funcionamente do dessalinizador solar proposto. O equipamento demostrou bom desempenho nessas condições, obtendo resultados significativos ao final dos ensaios.

O sistema de dessalinização solar proposto obteve rendimentos de aproximadamente $36 \%$, que se mostrou positivo se comparado à outros prototipos desenvolvidos na mesma região, o que mostra sua viabilidade de implantação, sendo assim uma alternativa para o tratamento de água salobra. Mesmo diante dos resultados 
obtidos não se pode inferir sobre a qualidade da água, já que as análises físico-químicas não foram possíveis de serem realizadas. Dessa maneira, sugere-se para trabalhos futuros verifiquem as características físico-químicas da água e outros ensaios como o microbiológico, para aferir potabilidade à água destilada proveniente do sistema. Por tanto, as modificações implementadas no protótipo desenvolvido por [5] se mostraram satisfatórias tendo um aumento considerável de eficiência.

\section{REFERÊNCIAS}

[1] Foster, R. E., \& Amos, W. (2005, August). Ten years of solar distillation application along the U.S.- Mexico border. Solar world congress.

[2] Mota, S., \& Andrade, M. A. N. (1986). Uso da Destilação Solar no Tratamento de Águas Contaminadas por Microrganismos. Aplicações às Pequenas Comunidade. Revista Tecnologia.

[3] CICCOLELLA, Chinappi; CARRIZO, Italia Jerez; CRIRINOS, Jesus Rosales. Destilador de água solar: alternativa para potabilizar água em zonas rurales eterminación de costos. Revista SABER - ULA. Venezuela. 2009.

[4] JORGE, Bruno Miguel Jacinto. Simulação de Processos de destilação solar de água salgada. 2011. $118 \mathrm{f}$. Disertação de Mestrado - Universidade Técnica de Lisboa, Lisboa, 2011.

[5] OLIVEIRA, Paulo Vinícius de Souza. Desenvolvimento de um destilador solar portátil com aplicação em comunidades rurais no Rio Grande do Norte. 2018. 12f. Trabalho de Conclusão de Curso - Universidade Federal Rural do Semi-árido, Mossoró - RN, 2018.

[6] MALUF, A. P. Destiladores solares no Brasil. Monografia do Departamento de Engenharia da Universidade Federal de Lavras do curso de Pós-Graduação Lato Sensu em Fontes Alternativas de Energia. UFLA, Minas Gerais, 2005.

[7] MARINHO, Franscisco José Loureiro. Et al. Dessalinizador solar associado a coletor de águas de chuva para fornecer água potável. In: SIMPÓSIO REGIONAL DE AGROECOLOGIA E DESENVOLVIMENTO RURAL SUSTENTAVEL, 15f, 2015, Goiânia. Enciclopédia Biosfera. Goiânia, 2015; p. 68.

[8] SILVEIRA, Maria Teresa Targino Macedo. Análise da aplicabilidade e desempenho térmico de um destiladorsolar em Mossoró-rn. 2014. 68 f. TCC (Graduação) - Curso de Ciência e Tecnologia, UFERSA, Mossoró, 2014.

[9] HOLANDA, Athayas Magalhães. Análise do Projeto de um Destilador Solar Caseiro. 2019. 50 f. TCC (Graduação) - Curso de Engenharia Mecânica, UFRN, Natal, 2019.

[10] BUROS, O. K.; et al. The USAID desalination manual. , Washington, D.C, Agency for international development 1980.

[11] Duffie, J., \& Beckman, W. (1991). Solar Engineering of Thermal Processes (2. ${ }^{a}$ ed.). New York: John Wiley and Sons.

[12] Tiwari, A. K., \& Tiwari, G. N. (2007). Thermal Modeling Based on Solar Fraction and Experimental Study of the Annual and Seasonal Performance of a Single Slope Passive Solar Still: The Effect of Water Depths. Desalination, 207, 184-204.

[13] CARVALHO, Bruno Soares. Aperfeiçoamento e análise térmica de um dessalinizador solar com cobertura piramidal. 2019. 10f. Trabalho de Conclusão de Curso - Universidade Federal Rural do Semi-árido, Mossoró $-\mathrm{RN}, 2019$. 